\title{
HYDROLOGICAL AND ECOLOGICAL EFFECTS OF CLIMATE CHANGE IN CAOHAI WATERSHED BASED ON SWAT MODEL
}

\author{
ZHOU, C. W. ${ }^{1}-$ YANG, R. $^{{ }^{*}}-$ YU, L. F. ${ }^{1}-$ ZHANG, Y. $^{1}-$ YAN, L. B. $^{1}$ \\ ${ }^{I}$ College of Life Sciences, Guizhou University, Guiyang, Guizhou, China \\ (e-mails: C.W. Zhou-changwei.1981@163.com; L.F.Yu-gdyulifei@163.com; L. B. Yan- \\ link_yan@126.com) \\ ${ }^{2}$ College of Forestry, Guizhou University, Guiyang, Guizhou, China \\ *Corresponding author \\ e-mail: yr553017@163.com
}

(Received $15^{\text {th }}$ Sep 2018; accepted $12^{\text {th }}$ Nov 2018)

\begin{abstract}
To understand the impact of meteorological changes on hydrological and water quality in Caohai watershed, Guizhou Province, China, based on the ArcGIS software, the land use map of Caohai watershed in 2017 was used to construct the land use database in the SWAT model, and then the soil database and the default meteorological database were used to establish the SWAT model of the Caohai Dongshan river watershed, the Zhonghe river watershed, the Baima river watershed and the Haizi river watershed. Sixteen climatic scenarios were set to simulate the hydrological response process of Caohai watershed. The results of the model analysis show that the variation of surface runoff and total nitrogen and phosphorus in each watershed is different when the temperature of the watershed rises by $1{ }^{\circ} \mathrm{C}$ and the precipitation remains unchanged. Under the same rainfall gradient, the surface runoff decreases with the increase of temperature; under the same temperature gradient, the surface runoff increases with the increase of rainfall, and the change of total nitrogen and phosphorus is more complex, which is related to the soil type and land cover.
\end{abstract}

Keywords: hydrological effects, ecological effects, climate change, SWAT model, Caohai

\section{Introduction}

Since the industrial revolution, with the rapid development of the industrial field, the concentration of greenhouse gases such as $\mathrm{CO}_{2}$ and $\mathrm{SO}_{2}$ in the atmosphere has increased, resulting in a global greenhouse effect, and the warming of the global climate (Ge et al., 2014). According to climate research in the past 50 years in China, the rate of the average temperature rise is the fastest in the north, and precipitation increases by different degrees in the southwest and west, the middle and lower reaches of the Yangtze river and the southeastern hilly areas. The precipitation increases most significantly in the western watershed, while precipitation decreases in north China, in the south, and in the northeast (Chen et al., 2019; Xiao and Tan, 2018; Zhao et al., 2018; Hu et al., 2013).

The study of water resources by climate change has become one of the most important environmental problems in the 21 st century (Solomon, 2007). Climate change affects the water cycle directly or indirectly by influencing regional temperature, precipitation, evaporation, etc. Therefore, the effect of climate change on hydrology is mainly studied by simulating the changes of meteorological factors to predict the effect of the possible increase or decrease of runoff on river watershed water resources (Liu et al., 2008). Vegetation conditions and local climate can interact with each other and climate change. It is an important factor in vegetation growth conditions, and the distribution of vegetation on the ground surface. Growth changes also affect regional 
climate (Wang et al., 2014). Specifically, climate affects the growth and distribution of vegetation, and at the same time the height of vegetation. The coverage is different, resulting in reflectance, underlying surface roughness and other surface bars. These differences will change regional climate conditions such as water cycle, Gas-heat cycle and so on. (Shen et al., 2015). The spatial distribution characteristics of vegetation restoration in the Loess Plateau are strip-like and consistent with the agroclimatic region. (He et al., 2015), and the effect of climate on vegetation is delayed (Zhang et al., 2016).

The ecosystem has undergone remarkable changes under the combined influence of climate change and human activities, and the study of the relationship between vegetation and these two has become the focus and core of scholars all over the world (Lu et al., 2017). Based on meteorological data Niu (2013) calculates runoff in and out of the river shutoff watershed for many years. Taking 1983-1987 as the base period, based on the hydrological parameters determined by SWAT-CUP software, a distributed hydrological model is used to simulate the runoff change of the river shutoff watershed.

The annual and seasonal mean temperatures in Guizhou Province have fluctuated and increased in the past 57 years, with an annual average heating rate of $0.13 \mathrm{C} / 10 \mathrm{a}$. The change of temperature in four seasons is significant, and the trend of change of autumn temperature and winter temperature is obviously higher (Zhu et al., 2018). This study aimed to understand the impact of meteorological changes on hydrological parameters and water quality in Caohai watershed.

\section{Research method}

\section{Study area profile}

Caohai is located in the eastern part of the Yunnan-Guizhou Plateau, in the northwestern part of Guizhou Province, on the southwest side of Weining Yi Nationality Hui and Miao Autonomous County in the Wumen Mountain (Ha et al., 2017) $\left(\mathrm{N} 26^{\circ} 49^{\prime}-26^{\circ} 53^{\prime}, \mathrm{E} 104^{\circ} 12^{\prime}-104^{\circ} 18^{\prime}\right)$. It is the largest natural lake and water area on the Guizhou Plateau. The Caohai reserve area is 96 square kilometers, and the water area is $20 \mathrm{~km}^{2}$. It belongs to the tropical monsoon humid climate zone. It is characterized by no severe cold in winter, no heat in summer, large daily temperature difference and small annual temperature difference. The average annual temperature is about 10.6, the minimum annual temperature is $1.7^{\circ} \mathrm{C}$, the highest annual temperature is $17.6{ }^{\circ} \mathrm{C}$, the average annual precipitation is $909 \mathrm{~mm}$, the average annual sunshine hours is $1800 \mathrm{~h}$, the frost-free period is 180 days, the dry and wet season are distinct. May-October is the rainy season, the rainfall in this period is accounted for $88 \%$ of the precipitation throughout the whole year, from December to March there is only 5\% of the total annual rainfall (Zheng et al., 2013; Xia et al., 2016).

\section{Data acquisition}

\section{Land use data acquisition}

Interpreting the high-definition image data of Caohai watershed $(2 \mathrm{~m} \times 2 \mathrm{~m})$ in 2017 for land use classification, the land use types in the study area are divided into six categories, and the land use codes were converted according to the model requirements. 
The converted land use codes were AGRL (cultivated land), FRSD (forest land), PAST (grassland), WATR (water area), URML (Construction land), SWRN (unused land).

\section{Soil data acquisition}

Based on the HWSD data and the world soil grid map, it is found that there are four main types of soil in the Caohai, namely, HAPLIC LUVISOLS1, HAPLIC LUVISOLS2,WATER BODIES,DUNES \& SHIFT.SANDS. The three variables missing in Chinese soil data, namely, SOL_BD of soil moisture density, SOL_AWC of effective water holding, and SOL_K of saturated water conductivity, need to be calculated by using SPAW software.

The method of estimating soil erosion factor $\mathrm{K}$, which was improved by Williams (1983) in EPIC model, is more convenient. Only soil organic carbon and soil particle data were used to estimate $\mathrm{K}$ value (Eqs. 1-5).

$$
\begin{aligned}
& K_{U S L E}=f_{\text {csand }} \times f_{\text {El }-s \mathrm{i}} \times f_{\text {orge }} \times f_{\text {hisand }} \\
& \left.f_{\text {csand }}=0.2+0.3 \times e^{\left[-0.256 \times M_{\text {mand }} \times\left(1-\frac{M_{\text {siln }}}{100}\right)\right.}\right] \\
& f_{e 1-s i}=\left(\frac{M_{\text {mili }}}{M_{\text {cllay }}+M_{\text {will }}}\right)^{0.3} \\
& f_{\text {orge }}=1-\frac{0.25 \times \text { org } C}{\operatorname{org} C+e^{(3.72-295)}}
\end{aligned}
$$

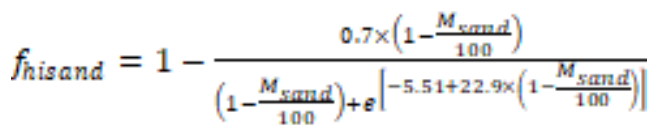

In the formula, $M_{\text {sand }}$ is the $0.05-2.00 \mathrm{~mm}$ sand content, $M_{\text {silt }}$ is the $0.002-0.05 \mathrm{~mm}$ clay content, $M_{\text {clay }}$ is the $0.02 \mathrm{~mm}$ powder content, $\operatorname{org} C$ is the organic carbon content.

\section{Acquisition of meteorological data}

Based on the meteorological data from SWAT meteorological database, the climate change in the study area is simulated.

\section{Results and analysis}

\section{Caohai sub watershed division}

Based on the generated river network map, the Caohai watershed was divided into four watersheds, namely Dongshan river watershed, Zhonghe river watershed, Baima river watershed, and Maojiahaizi river watershed. Then, the SWAT model was used to divide the -watersheds of each watershed. In the division of SWAT watershed, lake surface is selected as the outlet of each river watershed, and the specific watershed division of each river watershed is shown in Figure 1. 


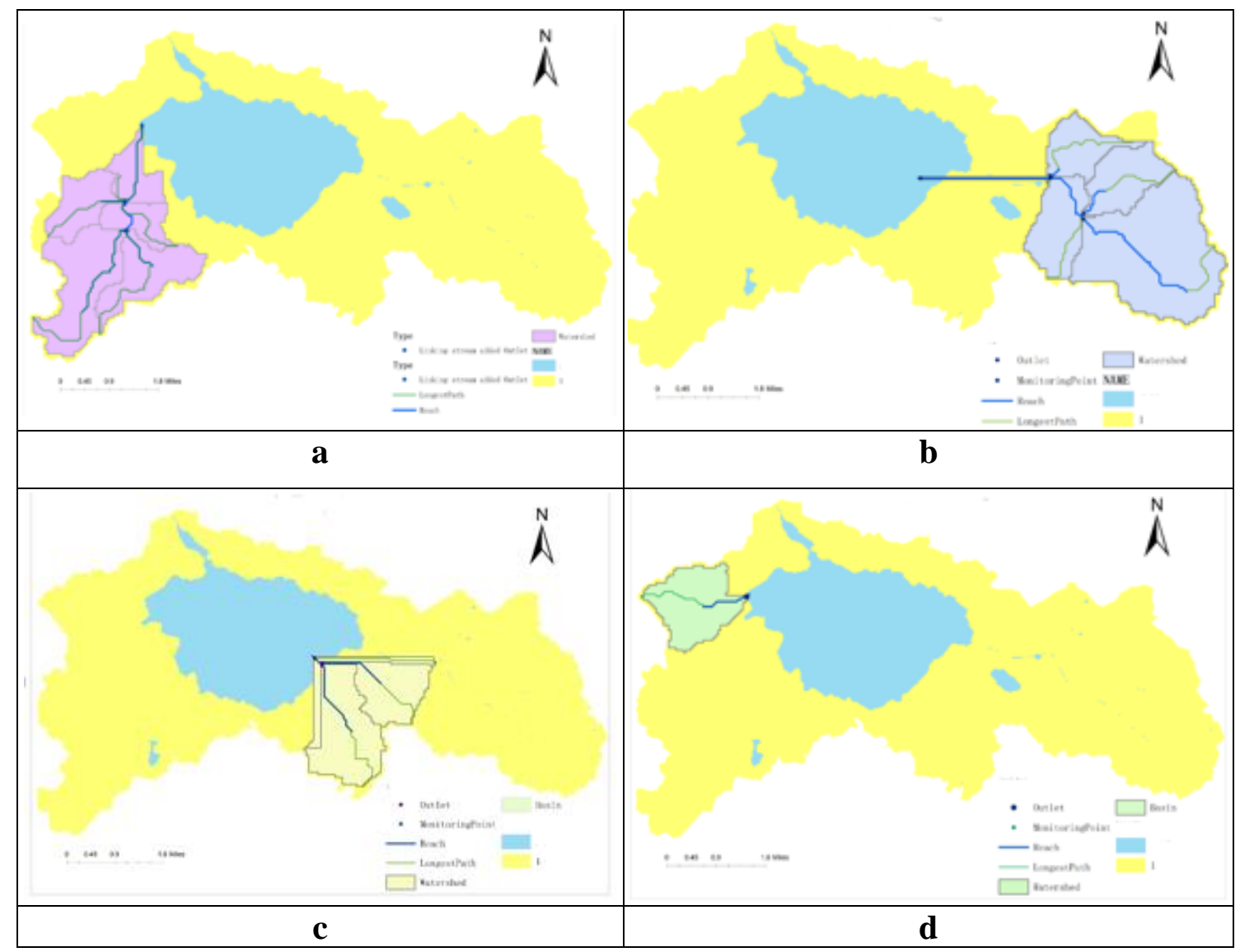

Figure 1. Sub watershed map of the area of the Maojiahaizi river watershed. a Dongshan river watershed, $\boldsymbol{b}$ Zhonghe river watershed, $\boldsymbol{c}$ Baima river watershed, $\boldsymbol{d}$ Maojiahaizi river watershed

\section{Analysis of response unit of hydrology to climate change}

The meteorological data have an important impact on the water cycle. Most of the rivers flowing into the Caohai are small rivers in the surrounding areas, most of which originate from springs. The supply of water resources in the Caohai is very limited. The reason why the Caohai can basically maintain the natural environment of the lakes and marshes is that the hydrogeological structure of the Caohai is conducive to the storage of surface water and groundwater, and the main recharge of surface water and groundwater in the Caohai area comes from precipitation. In the trend of global warming, meteorological factors will also change. In this paper, the response of hydrology to climate change in the Caohai watershed is carried out by simulating the changes of the temperature and precipitation values. The runoff of a river watershed is changed by local climatic conditions and the underlying conditions of the river watershed. Therefore, this paper analyzes the hydrological response to climate change in the Caohai watershed by changing the influence of temperature and precipitation on the annual average runoff, total nitrogen and total phosphorus of the Caohai.

Assume that the highest and lowest temperatures on the basis of the original were $+0{ }^{\circ} \mathrm{C},+1{ }^{\circ} \mathrm{C},+3{ }^{\circ} \mathrm{C},+5{ }^{\circ} \mathrm{C}$, annual precipitation change on the basis of the original were $-5 \%, 0 \%,+5 \%,+10 \%$, changing the SWAT model to the highest temperature of the meteorological database (TMPMX), the lowest temperature (TMPMN) and monthly total precipitation (PCPMM) it was used to simulate climate change in Caohai 
watershed runoff, and its influence to total nitrogen and phosphorus in the valley. Finally, the annual runoff (total nitrogen and phosphorus) and the percentage of annual runoff (total nitrogen and phosphorus) under unchanged climatic conditions were used to represent the change of annual runoff (b) (total nitrogen and phosphorus).

$$
\mathrm{b}=\frac{\left(y_{\mathrm{i}}-y_{0}\right)}{y_{0}} \times 100 \%
$$

In Equation 6: $y_{i}$ is the annual average runoff (total nitrogen and phosphorus) $\left(\mathrm{m}^{3} / \mathrm{s}\right)$ under the i climate scenario, $y_{0}$ is the annual average runoff (total nitrogen and phosphorus) $\left(\mathrm{m}^{3} / \mathrm{s}\right)$ without changing the climate conditions.

\section{Analysis of surface runoff in Caohai watershed under different climate scenarios}

Annual runoff data of watershed are derived from surface runoff of watershed during the simulation period (SURFACE RUNOFFQ) in the output summary file (OUTPUT.STD) of SWAT model. The analysis of each watershed is shown in Tables $1-4$.

In the rows of Table 1 it can be observed that when the temperature is constant, the rainfall decreases by $5 \%$ compared to the original value, the surface runoff decreases by $0.003 \%$, the rainfall increases by $5 \%$, the surface runoff increases by $0.007 \%$, the rainfall increases by $10 \%$, and the surface runoff increases by $0.013 \%$. When the temperature rises by $1{ }^{\circ} \mathrm{C}$, the precipitation decreases by $1.351 \%$, the precipitation decreases by $5 \%$, the surface runoff decreases by $1.371 \%$, the precipitation decreases by $0.02 \%$, the rainfall increases by $5 \%$, the runoff decreases by $1.341 \%$, the rainfall increases by $10 \%$, and the surface runoff decreases by $1.338 \%$.

In the columns of Table 1 it can be observed that in the case of constant rainfall, if the temperature rises by $1{ }^{\circ} \mathrm{C}$, the surface runoff decreases by $1.351 \%$; if the temperature rises by $3{ }^{\circ} \mathrm{C}$, the surface runoff decreases by $3.711 \%$; if the temperature rises by $5{ }^{\circ} \mathrm{C}$, the surface runoff of the watershed decreases by $5.348 \%$. When the rainfall increased by $5 \%$, the temperature increased by $1{ }^{\circ} \mathrm{C}$, the surface runoff decreased by $3.704 \%$, the temperature increased by $5{ }^{\circ} \mathrm{C}$, and the surface runoff decreased by $5.345 \%$.

Table 1. Runoff change rate under climate change scenarios in Dongshan river watershed

\begin{tabular}{c|c|c|c|c}
\hline \multirow{2}{*}{ Temperature change } & \multicolumn{4}{|c}{ Precipitation change } \\
\cline { 2 - 5 } & $\mathbf{- 5 \%}$ & $\mathbf{0 \%}$ & $\mathbf{+ 5 \%}$ & $\mathbf{+ 1 0 \%}$ \\
\hline $0^{\circ} \mathrm{C}$ & -0.003 & 0.000 & 0.007 & 0.013 \\
$1^{\circ} \mathrm{C}$ & -1.371 & -1.351 & -1.341 & -1.338 \\
$3{ }^{\circ} \mathrm{C}$ & -3.714 & -3.711 & -3.704 & -3.701 \\
$5^{\circ} \mathrm{C}$ & -5.352 & -5.348 & -5.345 & -5.342 \\
\hline
\end{tabular}

It can be seen from Table 2 that when the temperature rises by $0{ }^{\circ} \mathrm{C}$ and the precipitation decreases by $5 \%$, the surface runoff in the Zhonghe river watershed reduces by $0.006 \%$ compared with the climate-invariant scenario, the rainfall increases by $5 \%, 10 \%$, and the surface runoff increases by $0.006 \%$ and $0.013 \%$. When the temperature rises by $1{ }^{\circ} \mathrm{C}$, the rainfall is unchanged, the surface runoff reduces by 
$1.309 \%$; when the rainfall reduced by $5 \%$, the rainfall reduced by $1.324 \%$, which reduced by $0.15 \%$ compared with the same temperature and rainfall; The rainfall decreased by $5 \%$ and $10 \%$, and the runoff decreased by $1.296 \%$ and 1.289 respectively, which was increased by $0.013 \%$ and $0.02 \%$ compared with the same temperature and rainfall. When the temperature rises by $3^{\circ} \mathrm{C}$, the rainfall does not change, the surface runoff reduces by $3.118 \%$ compared with the climate constant scenario; when the rainfall reduces by $5 \%$, the surface runoff reduces by $3.125 \%$, when rainfall increased by $5 \%$ and $10 \%$, surface runoff decreased by $3.112 \%$ and $3.109 \%$ respectively, but it increased by $0.006 \%$ and $0.009 \%$ compared with the same temperature and rainfall, when the temperature rises by $5{ }^{\circ} \mathrm{C}$, the surface runoff decreases by $4.150 \%$, when the rainfall changes by $-5 \%,+5 \%,+10 \%$, the surface runoff changes little compared with the same temperature and rainfall.

Table 2. Runoff change rate under climate change scenarios in Zhonghe river watershed

\begin{tabular}{c|c|c|c|c}
\hline \multirow{2}{*}{ Temperature change } & \multicolumn{4}{|c}{ Precipitation change } \\
\cline { 2 - 5 } & $\mathbf{- 5 \%}$ & $\mathbf{0 \%}$ & $\mathbf{+ 5 \%}$ & $\mathbf{+ 1 0 \%}$ \\
\hline $0^{\circ} \mathrm{C}$ & -0.006 & 0.000 & 0.006 & 0.013 \\
$1{ }^{\circ} \mathrm{C}$ & -1.324 & -1.309 & -1.296 & -1.289 \\
$3{ }^{\circ} \mathrm{C}$ & -3.125 & -3.118 & -3.112 & -3.109 \\
$5{ }^{\circ} \mathrm{C}$ & -4.762 & -4.761 & -4.759 & -4.756 \\
\hline
\end{tabular}

In the columns of Table 3 it can be observed that the surface runoff is increasing with the increase of rainfall at the same temperature in the Baima river watershed. In the rows of the table it can be observed that under the same rainfall gradient, with the increase of temperature, the surface rainfall shows a trend of decreasing. When the temperature rises by $1{ }^{\circ} \mathrm{C}$, the rainfall increases by $0 \%$, and the surface runoff decreases by $1.127 \%$ compared with the climate-invariant scenario; When the rainfall decreased by $5 \%$, the surface runoff decreased by $1.138 \%$, which was $0.011 \%$ lower than the same temperature precipitation; The rainfall increased by $5 \%$ and $10 \%$ respectively, and the surface runoff increased by $0.002 \%$ and $0.004 \%$, which was $1.129 \%$ and $1.131 \%$ higher than the same temperature precipitation. When the temperature increased by $3{ }^{\circ} \mathrm{C}$ and 5 ${ }^{\circ} \mathrm{C}$, the rainfall did not change, and the surface runoff decreased by $2.966 \%$ and $4.150 \%$.

Table 3. Runoff change rate under climate change scenarios in Baima river watershed

\begin{tabular}{c|c|c|c|c}
\hline \multirow{2}{*}{ Temperature change } & \multicolumn{4}{|c}{ Precipitation change } \\
\cline { 2 - 5 } & $\mathbf{- 5 \%}$ & $\mathbf{0 \%}$ & $\mathbf{+ 5 \%}$ & $\mathbf{+ 1 0 \%}$ \\
\hline $0^{\circ} \mathrm{C}$ & -0.002 & 0.000 & 0.002 & 0.004 \\
$1^{\circ} \mathrm{C}$ & -1.138 & -1.127 & 0.002 & 0.004 \\
$3{ }^{\circ} \mathrm{C}$ & -2.968 & -2.966 & -2.965 & -2.964 \\
$5^{\circ} \mathrm{C}$ & -4.151 & -4.150 & -4.149 & -4.147 \\
\hline
\end{tabular}

In the rows of Table 4 it can be observed that under the condition of constant temperature, the precipitation decreases by $5 \%$ and the surface runoff decreases by $0.002 \%$; the precipitation increases by $5 \%$, the surface runoff increases by $0.002 \%$; the precipitation increases by $10 \%$, and the surface runoff increases by $0.005 \%$. 
In the columns of Table 4 it can be observed that when the temperature increases by $1{ }^{\circ} \mathrm{C}, 3{ }^{\circ} \mathrm{C}, 5{ }^{\circ} \mathrm{C}$, and the rainfall is constant, the surface runoff of the Maojiahaizi river watershed reduces by $1.258 \%, 3.338 \%$, and $4.538 \%$, respectively. At a temperature increase of $1{ }^{\circ} \mathrm{C}$, rainfall decreased by $5 \%$, surface runoff decreased by $1.277 \%$; rainfall increased by $5 \%$, surface runoff decreased by $1.254 \%$; rainfall increased by $10 \%$, and surface runoff decreased by $1.249 \%$.

Table 4. Runoff change rate under climate change scenarios in Maojiahaizi river watershed

\begin{tabular}{c|c|c|c|c}
\hline \multirow{2}{*}{ Temperature change } & \multicolumn{4}{|c}{ Precipitation change } \\
\cline { 2 - 5 } & $\mathbf{- 5 \%}$ & $\mathbf{0 \%}$ & $\mathbf{+ 5 \%}$ & $\mathbf{+ 1 0 \%}$ \\
\hline $0^{\circ} \mathrm{C}$ & -0.002 & 0.000 & 0.002 & 0.005 \\
$1^{\circ} \mathrm{C}$ & -1.277 & -1.258 & -1.254 & -1.249 \\
$3^{\circ} \mathrm{C}$ & -3.340 & -3.338 & -3.335 & -3.333 \\
$5^{\circ} \mathrm{C}$ & -4.540 & -4.538 & -4.537 & -4.535 \\
\hline
\end{tabular}

Analysis of changes of total nitrogen and phosphorus in Caohai watershed under different climate scenarios

The total nitrogen quantity data is the sum of organic nitrogen total amount (ORGN_OUT), ammonium nitrogen total amount (NH4_OUT), nitrate total amount (NO3_OUT) and nitrite total amount (NO2_OUT) in SWAT model output channel (.rch) file, and the unit is $\mathrm{kg}$. The total amount of phosphorus is the sum of the total amount of organic phosphorus (ORGP_OUT) and the total amount of mineral phosphorus (MINP_OUT) in channel (.rch) files, and the unit is $\mathrm{kg}$. The change rate of total nitrogen in each watershed is shown in Tables 5, 7, 9 and 11, and the rate of change of total phosphorus in Tables 6, 8,10 and 12.

Table 5. Change rate of total nitrogen in Dongshan river watershed

\begin{tabular}{c|c|c|c|c}
\hline \multirow{2}{*}{ Nemperature change } & \multicolumn{4}{|c}{ Precipitation change } \\
\cline { 2 - 5 } & $\mathbf{- 0 . 0 5 \%}$ & $\mathbf{0 \%}$ & $\mathbf{0 . 0 5 \%}$ & $\mathbf{0 . 1 \%}$ \\
\hline $0^{\circ} \mathrm{C}$ & 0 & 0 & -0.154 & -0.1472 \\
$1^{\circ} \mathrm{C}$ & -1.349 & -1.5623 & -1.5085 & -1.5051 \\
$3{ }^{\circ} \mathrm{C}$ & 2.9656 & 2.7997 & 2.8078 & 2.814 \\
$5^{\circ} \mathrm{C}$ & -8.1034 & -8.2702 & -8.2645 & -8.2569 \\
\hline
\end{tabular}

Table 6. Change rate of total phosphorus in Dongshan watershed

\begin{tabular}{c|c|c|c|c}
\hline \multirow{2}{*}{ P } & \multicolumn{4}{|c}{ Precipitation change } \\
\cline { 2 - 5 } Temperature change & $\mathbf{- 0 . 0 5 \%}$ & $\mathbf{0 \%}$ & $\mathbf{0 . 0 5 \%}$ & $\mathbf{0 . 1 \%}$ \\
\hline $0^{\circ} \mathrm{C}$ & 0 & 0 & -0.033 & -0.0224 \\
$1^{\circ} \mathrm{C}$ & -0.2561 & -0.3597 & -0.2813 & -0.2761 \\
$3{ }^{\circ} \mathrm{C}$ & 0.6959 & 0.6516 & 0.658 & 0.667 \\
$5{ }^{\circ} \mathrm{C}$ & 0.9719 & 0.9253 & 0.9331 & 0.9398 \\
\hline
\end{tabular}


It can be seen from Table 5, under the condition of constant temperature, the precipitation decreased by 5\%, the total nitrogen content in the Dongshan watershed did not change compared with the precipitation; when the precipitation increases by $5 \%$, the total nitrogen in the watershed decreases by $0.1540 \%$. When the precipitation decreases by $10 \%$, the total nitrogen decreases by $0.1472 \%$, which means a $0.0068 \%$ increase compared with the previous gradient. When the temperature increases by $1{ }^{\circ} \mathrm{C}$ and the precipitation is constant, the total nitrogen in the watershed decreases by $1.5623 \%$; if the precipitation decreases by $5 \%$, the total nitrogen in the watershed decreases by $1.3490 \%$, the rainfall increases by $5 \%$ and $10 \%$, and the total nitrogen in the watershed decreases by $1.5085 \%$ and 1.5051 respectively. Under the condition of constant precipitation, when the temperature increased by $1{ }^{\circ} \mathrm{C}$, the total nitrogen decreased by $1.5623 \%$; the temperature increased by $3{ }^{\circ} \mathrm{C}$, the total nitrogen in the watershed increased by $2.9977 \%$; when the temperature increased by $5{ }^{\circ} \mathrm{C}$, the total nitrogen decreased by $8.2702 \%$.

It can be seen from Table 6 that in the case of a temperature increase of $1{ }^{\circ} \mathrm{C}$, the rainfall does not change, the total phosphorus content in the Dongshan watershed decreases by $0.3597 \%$; the rainfall decreases by $5 \%$, the total phosphorus decreases by $0.2561 \%$; and the precipitation increases by 5\%. Total phosphorus decreased by $0.2813 \%$; precipitation increased by $10 \%$ and precipitation decreased by $2.761 \%$. In the case of $5 \%$ reduction in precipitation, the temperature did not change, the total phosphorus in the watershed did not change; if the temperature increased by $1{ }^{\circ} \mathrm{C}$, the total phosphorus in the watershed decreased by $0.2561 \%$; the temperature increased by $3{ }^{\circ} \mathrm{C}, 5{ }^{\circ} \mathrm{C}$, the total phosphorus in the watershed increased by $0.6595 \%$ and $0.9719 \%$, respectively.

In the rows of Tables 5 and 6 it can be seen that under the same temperature gradient, with the increase of rainfall, the total nitrogen and total nitrogen in the watershed showed a decreasing trend first and then an increasing one. In the rows, under the same precipitation gradient, with the increase of temperature, the total nitrogen in the watershed decreased first, then increased and then decreased. The total phosphorus in the watershed decreased first and then increased.

It can be seen from Table 7, under the condition of constant temperature, the precipitation decreased by $5 \%$, the total nitrogen in the Zhonghe river watershed increased by $6.022 \%$, the precipitation increased by $5 \%, 10 \%$, and the total nitrogen in the watershed increased by $0.0027 \%$ and $0.0177 \%$. Under the condition of constant precipitation, the temperature increased by $1{ }^{\circ} \mathrm{C}$, the total nitrogen in the watershed decreased by $2.4135 \%$; the temperature increased by $3{ }^{\circ} \mathrm{C}$, the total nitrogen increased by $0.0274 \%$; the temperature increased by $5{ }^{\circ} \mathrm{C}$, the total nitrogen decreased by $7.2739 \%$.

Table 7. Change rate of total nitrogen in Zhonghe river watershed

\begin{tabular}{c|c|c|c|c}
\hline $\mathbf{N}$ & \multicolumn{4}{|c}{ Precipitation change } \\
\cline { 2 - 5 } Temperature change & $\mathbf{- 5 \%}$ & $\mathbf{0 \%}$ & $\mathbf{5 \%}$ & $\mathbf{1 0 \%}$ \\
\hline $0^{\circ} \mathrm{C}$ & 6.0022 & 0 & 0.0027 & 0.0177 \\
$1^{\circ} \mathrm{C}$ & -1.7208 & -2.4135 & -2.2964 & -2.2911 \\
$3^{\circ} \mathrm{C}$ & 0.6122 & 0.0274 & 0.0388 & 0.042 \\
$5{ }^{\circ} \mathrm{C}$ & -6.6919 & -7.2739 & -7.2753 & -7.2763 \\
\hline
\end{tabular}


It can be seen from Table 8 , under the condition of constant temperature, rainfall decreased by $5 \%$, total phosphorus in the Zhonghe river watershed increased by $10.4262 \%$, rainfall increased by $5 \%$, total phosphorus increased by $0.6644 \%$. Rainfall increased by $10 \%$ and total phosphorus increased by $0.6746 \%$. Under the condition of constant precipitation, in the case of a $1^{\circ} \mathrm{C}$ temperature rise, total phosphorus in the Zhonghe river watershed decreased by $1.1845 \%$; if the temperature increased $3{ }^{\circ} \mathrm{C}$, the total phosphorus decreased 1.1675\%; the rainfall increased by $10 \%$ and the total phosphorus decreased by 1.1535 .

Table 8. Change rate of total phosphorus in Zhonghe river watershed

\begin{tabular}{c|c|c|c|c}
\hline \multirow{2}{*}{$\begin{array}{c}\mathbf{P} \\
\text { Temperature change }\end{array}$} & \multicolumn{4}{|c}{ Precipitation change } \\
\cline { 2 - 5 } & $\mathbf{- 5 \%}$ & $\mathbf{0 \%}$ & $\mathbf{5 \%}$ & $\mathbf{1 0 \%}$ \\
\hline $0{ }^{\circ} \mathrm{C}$ & 10.4262 & 0 & 0.6644 & 0.6746 \\
$1{ }^{\circ} \mathrm{C}$ & -1.1399 & -1.1845 & -1.0791 & -1.0778 \\
$3{ }^{\circ} \mathrm{C}$ & -1.218 & -1.1675 & -1.1619 & -1.1535 \\
$5{ }^{\circ} \mathrm{C}$ & -0.9862 & -0.9346 & -0.9367 & -0.9335 \\
\hline
\end{tabular}

In the rows of Tables 7 and 8 it can be observed that under the same temperature gradient, the total nitrogen and total phosphorus in the watershed decreased first and then increased. In the columns it can be seen that under the same precipitation gradient, the total nitrogen in the watershed decreases first and then increases, while the total phosphorus in the watershed decreases first and then increases.

It can be seen from Table 9, when the temperature rises by $3{ }^{\circ} \mathrm{C}$, the rainfall decreases by $5 \%$, then increases by $5 \%$ and $10 \%$, and the total nitrogen increases by $5.9643 \%, 5.9486 \%, 5.9487 \%$ and $5.9527 \%$ respectively. Under the same precipitation gradient, the precipitation remained unchanged, the temperature increased by $1{ }^{\circ} \mathrm{C}$, $3{ }^{\circ} \mathrm{C}$, and the total nitrogen content in the Baima river watershed increased by $2.9442 \%$, $5.9643 \%$. When the temperature increased $5{ }^{\circ} \mathrm{C}$, the total nitrogen content of the watershed decreased by $11.2602 \%$.

Table 9. Change rate of total nitrogen in Baima river watershed

\begin{tabular}{c|c|c|c|c}
\hline \multirow{2}{*}{ N } & \multicolumn{4}{|c}{ Precipitation change } \\
\cline { 2 - 5 } Temperature change & $\mathbf{- 5 \%}$ & $\mathbf{0 \%}$ & $\mathbf{5 \%}$ & 0.0099 \\
\hline $0^{\circ} \mathrm{C}$ & 0.0182 & 0 & 0.0053 & 2.934 \\
$1^{\circ} \mathrm{C}$ & 2.9442 & 2.9124 & 5.9315 & 5.9527 \\
$3^{\circ} \mathrm{C}$ & 5.9643 & 5.9486 & -11.2789 & -11.2776 \\
$5^{\circ} \mathrm{C}$ & -11.2602 & -11.2805 & \multicolumn{10}{c}{} \\
\hline
\end{tabular}

It can be seen from Table 10 , when the temperature rises by $5{ }^{\circ} \mathrm{C}$, the rainfall does not change, the total phosphorus content in the Baima river watershed increases by $4.2445 \%$; the rainfall decreases by $5 \%$, the total phosphorus increases by $4.4471 \%$; the rainfall increases by 5\%, 10\%. The total phosphorus increased by $4.2425 \%$ and $4.2473 \%$. Under the condition of constant precipitation, the temperature increases by $1{ }^{\circ} \mathrm{C}, 3{ }^{\circ} \mathrm{C}$, and $5{ }^{\circ} \mathrm{C}$, and the total phosphorus content in the watershed increases by $0.9561 \%, 4.0261 \%$, and $4.2445 \%$, respectively. 
Table 10. Change rate of total phosphorus in Baima river watershed

\begin{tabular}{c|c|c|c|c}
\hline \multirow{2}{*}{ P } & \multicolumn{4}{|c}{ Precipitation change } \\
\cline { 2 - 5 } Temperature change & $\mathbf{- 5}$ & $\mathbf{0}$ & $\mathbf{5}$ & $\mathbf{1 0}$ \\
\hline $0^{\circ} \mathrm{C}$ & 0.1993 & 0 & 0.0057 & 0.0185 \\
$1{ }^{\circ} \mathrm{C}$ & 1.2247 & 0.9561 & 1.0357 & 1.0414 \\
$3^{\circ} \mathrm{C}$ & 4.2266 & 4.0261 & 4.0309 & 4.0413 \\
$5^{\circ} \mathrm{C}$ & 4.4471 & 4.2445 & 4.2425 & 4.2473 \\
\hline
\end{tabular}

In the rows of Tables 9 and 10 it can be seen that the total nitrogen and phosphorus in the watershed decrease first and then increase with the increase of rainfall under the same temperature gradient. In the columns it is shown that with the same precipitation gradient, the total nitrogen increases first and then decreases, while the total phosphorus increases.

It can be seen from Table 11, under the condition of constant temperature, if the precipitation decreases by $5 \%$, the total nitrogen in the Maojiahaizi river watershed is decreases by $0.0357 \%$, if the precipitation increases by $5 \%$ and $10 \%$, the total nitrogen in the watershed increases by $0.0090 \%$ and $0.0100 \%$. Under the condition of constant precipitation, if the temperature increased by $1{ }^{\circ} \mathrm{C}$ and $3{ }^{\circ} \mathrm{C}$, the total phosphorus content in the watershed increased by $1.3782 \%$ and $4.6177 \%$, respectively; if the temperature increased by $5{ }^{\circ} \mathrm{C}$, and the total phosphorus decreased by $12.0781 \%$.

Table 11. Change rate of total nitrogen in Maojiahaizi river watershed

\begin{tabular}{c|c|c|c|c}
\hline \multirow{2}{*}{ N } & \multicolumn{4}{|c}{ Precipitation change } \\
\cline { 2 - 5 } Temperature change & $\mathbf{- 5 \%}$ & $\mathbf{0 \%}$ & $\mathbf{5 \%}$ & $\mathbf{1 0 \%}$ \\
\hline $0^{\circ} \mathrm{C}$ & -0.0357 & 0 & 0.009 & 0.018 \\
$1{ }^{\circ} \mathrm{C}$ & 1.3715 & 1.3782 & 1.4056 & 1.4056 \\
$3{ }^{\circ} \mathrm{C}$ & 4.6284 & 4.6617 & 4.665 & 4.6688 \\
$5^{\circ} \mathrm{C}$ & -12.1102 & -12.0781 & -12.0757 & -12.0695 \\
\hline
\end{tabular}

It can be seen from Table 12, under the condition of constant precipitation, the temperature increases by $1{ }^{\circ} \mathrm{C}$, the total phosphorus content in Haizi river watershed decreases by $0.3844 \%$, the temperature increases by $3{ }^{\circ} \mathrm{C}, 5{ }^{\circ} \mathrm{C}$, and the total phosphorus content in the watershed increases by $0.7536 \%, 1.2348 . \%$.

Table 12. Change rate of total phosphorus in Maojiahaizi river watershed

\begin{tabular}{c|c|c|c|c}
\hline \multirow{2}{*}{$\begin{array}{c}\mathbf{P} \\
\text { Temperature change }\end{array}$} & \multicolumn{4}{|c}{ Precipitation change } \\
\hline $0^{\circ} \mathrm{C}$ & 0.2005 & $\mathbf{0 \%}$ & $\mathbf{5 \%}$ & $\mathbf{1 0 \%}$ \\
$1{ }^{\circ} \mathrm{C}$ & -0.1152 & 0 & 0.0088 & 0.0247 \\
$3{ }^{\circ} \mathrm{C}$ & 0.954 & -0.3844 & -0.2987 & -0.2987 \\
$5{ }^{\circ} \mathrm{C}$ & 1.4402 & 1.2348 & 0.7605 & 0.7667 \\
& & & 1.2495 & -1.2836 \\
\hline
\end{tabular}


In the rows of Tables 11 and 12, under the same temperature gradient, with the increase of rainfall, the total nitrogen content of Haizi river Watershed increased, and the total phosphorus decreased first and then increased. In the columns, the total nitrogen in the watershed showed a trend of increasing first and then decreasing, and the amount of total phosphorus first decreased and then increased.

\section{Discussion and conclusion}

(1) A study on the hydrological response of 16 climate scenarios was carried out for the SWAT model of the Caohai watershed: On the same rainfall gradient, the runoff of the watershed decreases with the increase of temperature, and on the same temperature gradient, the surface runoff of the watershed increases with the increase of rainfall.

(2) Through the analysis of the change of total nitrogen and phosphorus simulated by the model, under the same climate scenario, the change rate of total nitrogen and phosphorus is different in different river watersheds. for example, when precipitation is constant, the temperature increases by $5{ }^{\circ} \mathrm{C}$. Total nitrogen decreased $8.2702 \%$ and total phosphorus increased $0.9253 \%$ in Dongshan river watershed. The total nitrogen decreased $7.2739 \%$ and the total phosphorus decreased $0.9346 \%$ in the Zhonghe river watershed; the total nitrogen decreased $11.2805 \%$ in the Baima river watershed and the total phosphorus increased $4.2445 \%$; the total nitrogen decreased $12.7081 \%$ and the total phosphorus $1.2348 \%$ in the Haizi river watershed. In different climate scenarios, the trend of total nitrogen and phosphorus change is different, and the change of nitrogen and phosphorus is related to a series of complex factors such as land cover and soil type of watershed.

Acknowledgements. This work was supported by the Major Project of Guizhou Province (Qian Ke He Major Project Zi [2016]3022-06), the Application Foundation Major Project of Guizhou Province (Qian Ke He JZ Zi [2014] 200211), the Construction Program of Biology First-class Discipline in Guizhou (GNYL [2017] 009), the Key Discipline Construction Project of Ecology in Guizhou Province (Guizhou Degree ZDXK[2016]7)

\section{REFERENCES}

[1] Bao, G., Tan, Z., Bao, Y. et al. (2013): 1982-2006 vegetation cover in Mongolia Plateau spatial-temporal variations of cover. - Desert of China 33(3): 918-927.

[2] Chen, Y., Zhang, R., Wang, Y., Fan, Z., Chen, F. (2019): Climate and hydrological changes indicated by spruce tree ring width in the upper reaches of Nujiang River. Resources and environment in arid areas. - 33(1): 126-130.

[3] Ge, Q., Wang, F., Wang, S., Cheng, B. (2014): Definition and uncertainty of seven questions concerning global warming. - China Population, Resources and Environment, 1: $1-6$.

[4] Han, Z., Zhangshui, W., Cao, X. T. (2017): Distribution characteristics of nitrogen and phosphorus and estimation of sediment release flux in Caohai, Guizhou. - Journal of Ecology 9: 2501-2506.

[5] He, Y., Yao, W., Zhang, Y., et al. (2015): Spatial variability of vegetation restoration on the Loess Plateau based on MODIS/NDVI. - China Soil and Water Conservation Science 13(2): 63. 
[6] Hu, H., Huang, G., Huang, H. (2013): Analysis of runoff variation and its influencing factors at Tieling Station in Liaohe River Watershed. Soil and water conservation study.2: 98-102.

[7] Liu, C., Liu, X., Zheng, H. (2008): Discussion on the impact of climate change on hydrology and water resources. - Science and Society 2: 21-27.

[8] Liu, Z., Shao, Q. Q. (2014): Vegetation cover change in Sanjiang source area and its relationship with gas relationship between phenological factors. - Study on Soil and Water Conservation 21(6): 334-339.

[9] Lu, Q., Wu, S., Zhao, D. Alpine grasses on the Qinghai-Tibet Plateau from 1982 to (2017): Land cover change and its relationship with climate. - Geographic Science 37(2): 29-300.

[10] Niu, L. (2013): The Impact of Climate and Land Use Change on Runoff Based on SWAT. - Central China Normal University, Wuhan.

[11] Shen, M., Piao, S., Jeong, S. J. et al. (2015): Evaporative cooling over the Tibetan Plateau induced by vegetation growth. - Proceedings of the National Academy of Sciences of the United States of America 112(30): 9299.

[12] Solomon, S. D., Qin, M., Manning, Z., Chen, M., Marquis, K. B., Averyt, M. T., Miller, H. L. (2007): IPCC 2007. Climate Change 2007: The physical science basis. Contribution of Working Group I to the Fourth Assessment Report of the Intergovernmental Panel on Climate Change. - Computational Geometry 2: 1-21.

[13] Tan, J. (2018): Characteristics and causes of the main mode variation of summer rainfall anomalies in the Yangtze River Basin, Xiao Zhixiang. - Plateau Meteorology 5: 13041312.

[14] Wang, Y., Feng, J., Gao, H. (2014): Numerical simulation of the impact of land cover change on regional climate in China. - Theoretical \& Applied Climatology 115: 141.

[15] Williams, J. R., Renard, K. G., Dyke, P. T. (1983): EPIC-A New Method for Assessing Erosion's Effect on Soil Productivity. - Journal of Soil \& Water Conservation 38(5): 381383.

[16] Xia, P., Kong, X., Yu, L. (2016): Effects of land use and landscape pattern on nitrogen and phosphorus output in small watershed of Caohai Wetland. - Journal of Environmental Sciences 8: 2983-2989.

[17] Zhang, H., Fang, N., Shi, Z. (2016): Spatiotemporal patterns for the NDVI and its responses to climatic factors in the Loess Plateau, China. - Acta Ecological Sinca 36(13): 3960.

[18] Zhang, Q., Wang, Q., Zhang, C., et al. (2014): Changes of grassland vegetation coverage and their driving power: take Maqu County, Gannan Tibetan Autonomous Prefecture as an example. - China's Agricultural Resources Zoning 35(4): 58-62.

[19] Zhao, G., Han, Y., Liu, M., Hou, J., Shi, H., Liu, W., Guo, Y., Qiao, Q. (2018): Spatial and temporal characteristics of extreme precipitation events in Henan Province from 1961 to 2013. - Soil and Water Conservation Research 25(06): 115-120.

[20] Zheng, J., Xia, P., Lin, T., Zhou, Y. 2013 . Nitrogen and phosphorus contents and distribution characteristics of farmland ditches in the suburb of Caohai, Guizhou. Mountain Agrobiology 3: 224-228.

[21] Zhu, D., Xiong, K., Dong, X. (2018): Spatial and temporal variation of temperature in Guizhou from 1960 to 2016. - Study on Soil and Water Conservation 25(4): 168$173+180$. 